shining bluish gray. As it dries, under the influence of gravitation the blue venous tint fades out of the gray and the wall becomes pink tinged. Presently it assumes the appearance of parchment, and sometimes it appears painted at rare intervals with ramifying little arteries which are crowded and overlapped by the larger companion veins; the latter are less arborescent and more suddenly dive and disappear in the bowel wall. In time, over all there comes a sheen as of collodion varnish and the vascular pictures fade save that one beneath the promonotory of the sacrum. These phenomena appear exactly as described only in the healthy rectum; in the diseased organ the color varies much.

Should the operator deviate from the prescribed directions for the manipulation of his fingers and so twist his hands as to divulse the anus in the anteroposterior direction instead of laterally he invites de. feat upon himself; for in the male the fixation of the perineum and the immobility of the coccyx interfere with the requisite dilatation; while in the female, the extreme mobility of the perineum and particularly the backward displaceability of the coccyx will allow such traction to be made upon the levatores ani as to pull their inner borders parallel and almost together, and in consequence the wider the female's anus be opened anterio-posteriorly the closer it shuts laterally to rob us of our view.

1077 Prospect Street.

\section{PRIMARY CARCINOMA OF THE AXILLA.}

Presented to the Section on Surgery and Anatomy at the Forty-ninth Annual Meeting of the American Medical Association, held at Denver, Colo., June 7-10, 1898.

BY D. W. GRAHAM, M.D.

CHICAGO, ILL.

Carcinoma of the axilla consecutive to a primary focus of the disease in the mammary gland, or some other organ or structure, is a matter of almost daily occurrence in the experience of the surgeon. But primary carcinoma of the axillary region is rare enough to be worthy of discussion, especially as it raises some important questions in the fields of histologic anatomy and pathology, and of practice. There is no apparent reason why this region might not be the site of the squamous celled, or true skin carcinoma, as frequently as any other in the body. Primary cancer of the axillary skin is, however, exceedingly rare. Of 7297 primary cases of carcinoma analyzed by Williams 571 were of the skin, but of these latter only three were axillary.

There is no doubt but that occasionally a primary carcinoma of the breast will first manifest itself clinically through the infection and enlargement of the axillary lymphatics. The primary nodule, small, slowly-growing and deeply seated, and the conditions present for quick invasion and rapid progress of the lymphatic infection would give a pathologically secondary, but a clinically primary tumor in the axilla. While this is the explanation usually given and generally accepted for most carcinomatous tumors first appearing in this region it is applicable only to a small number of such cases, and should not apply except when the axillary tumor shows an exclusively lymphatic histologic basis.

There are two structures found in the axillary space in which carcinoma is prone to originate, which will account for nearly all cases of true primary carcinoma in this region. One of these is the supernumerary mammary gland tissue more or less perfect or rudimentary, found occasionally, and the other structure constitutes the large convoluted, tubular sweat glands, which are constantly present.

The most complete recent exposition of the subject of supernumerary mammary glands in the human subject is that by W. R. Williams in the Journal of Anatomy and Physiology, Vol. xxv, 1891. It is shown that there may be one, two, or three of these above the normal gland on a line diverging outward to the axilla-two on the border of the pectoral muscle, and one in the base of the axilla. The latter is the least frequent. Most frequently these supernumeraries are rudimentary masses lying wholly beneath the skin and neither visible nor palpable, resembling in gross appearance ordinary subcutaneous connective tissue, but microscopically they show some of the normal elements of the gland. These subcutaneous "mammary lumps," as they have been called, may be wholly detached from each other and from the normal mam. mary gland, or they may be joined to the latter by an isthmus of the same kind of rudimentary tissue. In 132 consecutive cases of carcinoma in the mam. mary region in females Williams found that 13 of them had their origin in supernumerary structures quite outside the normal glands. None of these, however, were located in the axilla proper.

The sweat glands of the human axilla have been specially described by such anatomists as Sappey, Koelliker and others, but it remained for C. H. Creighton to demonstrate their peculiarities and em. phasize their significance from a pathologic standpoint. In the Royal Medico-Chirurgical Society transactions of 1882, Vol. lxv, page 53, he reports three cases of axillary carcinoma in dogs, originating in the large axillary sweat glands. Spencer Wells, in Wood's Monographs, Vol. iii, No. 1, 1889, reports a case of axillary carcinoma with the microscopic findings which seem to demonstrate that it originated in the large, tubular sweat glands in the manner described by Creighton. They are regarded as a kind of rudimentary organ of cutaneous secretion in the human when compared with similar structures in the lower animals, and, as Wells observes, are subject to all the risks of such survivals or rudiments. These glands, while also found in the groin and in the areola of the breast as well, are looked upon as midway in structure, with their large acini and amount of secreting surface, between the ordinary sweat glands and the mammary gland. They have their distinguishing histologic features by which they can be identified with ease. They are situated under the skin and not in the skin like other sweat glands and their ducts open into the hair follicles. They are large enough to be detected as firm, round bodies in the subcutaneous tissues in a dissection. It is quite probable that a more careful study of specimens of primary axillary tumors would show these glandular structures to be the point of departure for the morbid process in the majority of cases, rather than the supposed axillary supernumerary mass of mammary tissue. A study of the clinical histories also of those cases which have been put on record is suggestive in this same direction. The two following cases have served as a basis for this brief paper on this subject:

Case 1.-Miss DeC., aged 50 years, came into my hospital service in June, 1898. The right axilla was filled with a hard mass which was already causing edema of the arm by pressure. 
The history and physical characteristics all pointed to carcinoma. Nothing abnormal could be detected in the breast nor in the tissues intervening between this and the tumor. Removal of the grow th required an unusually difficult dissection, a section of the axillary vein being extirpated with the mass, Six monthe later the patient returned with a nodule not larger than the end of a finger, just beneath the skin, about the mid. dle of the upper hemisphere of the mammary gland. The skin was involved and adherent to the nodule. The breast was amputated by my colleague and a microscopic examination was made by Dr. William E. Schroeder, who had already examined the tumor removed six months before from the axilla. Both specimens were demonstrated to be carcinoma.

Case 2.-Mrs. A. C., 30 years of age; had had acute mastitis with suppuration while nursing a child in 1895. The exam. ination, December, 1897, revealed a hard tumor in the base of the right axilla as large as a hen's egg, and which had been developing for a number of months. There were several small nodules, which had developed later, extending along the bor der of the pectoral muscle toward the breast. The latter was equally consistent throughout and except that it was firmer and slightly larger than the left breast, it seemed to be perfectly normal. The main tumor was movable, and to all appearances did not involve the overlying integument. The several smaller nodules seemed to be enlarged lymphatic glands.

The operation consisted in removing both the tumor and the breast, together with the isthmus of in tervening infected tissue. Dr. L. Hektoen made a careful microscopic examination of the specimens and reported there was no carcinoma of the breast proper, it being, however, in a state of chronic inflammation. The ducts were much enlarged and dilated, filled with semisolid secretion, cheesy like and surrounded throughout the whole breast and nipple by hyaline connective tissue. The main tumor from the axilla was simple carcinoma with consid. erable fibrous tissue, and the intervening lymphatice were some of them carcinomatous, and the opinion was expressed that the nodule nearest the mammary gland was an outlying accessory portion of the gland, although before the operation there seemed to be a clear intervening space between them.

It is to be regretted that in neither of these cases did it seem possible to demonstrate by the microscopic examination the exact anatomic structure or charac. teristics of the tissue in which the carcinoma appeared.

After a thorough search of medical literature I have been unable to find but eighteen reported cases of primary carcinoma of the axilla which can be accepted as such. I have rejected a number of those that have been so reported, because the evidence shows that they were either sarcoma or secondary carcinoma. Even two or three of these eighteen, which follow, might prove to be sarcoma if fuller histories were obtainable or if the specimens had been microscopically examined since the time when there began to be histologic differentiation between sarcoma and carcinoma.

Case 1.-H. Snow, London Lancet, March 12, 1898, p. 717. Female, aged 47. Hard mass, filled whole axilla. One and a half years' duration. Skin adherent. Breast healthy, but removed with tumor because the disease seemed to be traveling toward the mammary gland, the normal direction of infection being cut off.

Case :-C. E. N. Keily, London Lancet, March 26,1898, p. 859, Female aged 80. Tumor size of pigeon's egg in middde of axilla at fourth rib. Hard and fixed to the chest wall. Skin ulcorated. No apparent connection with breast. No operation. Its course was watched and it extended gradually along the border of the pectoral muscle to the breast, which became involved. No lyınphatic glandular enlargement. The opinion is expressed that the tumor did not originate in an outlying free nodule of mammary gland tissue.

Case :--F. P. Paul, Transactions Patholngical Society London, 1895, Vol xlvi, p. 153. Female aged 29. Tumor appeared in axilla while nursing child, then disappeared, and reappeared when nursing next child and took on all the characteristies of typical scirrhus. Tumor excised. No connection with the mammary gland. Cut section exuded white secretion, like inspissated milk. Thinks it originated in sweat glands. but this opinion is controverted by Williams, who believed it arose from a detached axillary mammary lobule. (British Medical Journal, 1894, Vol. ii, p. 1405.)

Case 4.--H. Walton, Medical Press and Circular, London, 1895, Vol. ii, p. 45. Primary hard cancer in axilla. Operation.
Several recurrences. Subsequent operation. Immunity of the breast from cancer.

Case 5. - Spencer Wells, Wood's Med. and Sur. Monographs, 1889, Vol. iii, p. 18. "Cancer and Cancerous Diseases." A case of axillary tumor removed. Female aged 46. Microscopic examination showed origin in the sweat glands. Breast free from disease.

Case 6.--Bailly, Le Progrès Medicale, Second Series, 1887, Vol. v, p. 53. Female aged 68. Tumor of right axilla. Three years' duration. No connection with mammary gland. Microscope showed hard carcinoma.

Case 7.--Pied. Bulletin Société Méd. de la Tours, 1886, Vol. xxvii, p. 62. Carcinomatous tumor of the axilla. Extirpation. Case 8.-J. Congoureux, Gaz. Med. Chi., Tolouse, 1881, Vol. xiii, p. 137. Voluminous carcinoma developea spontaneously in the right axilla without morbid change of the breast.

Case 9.-J. Coates, Glasgow Med. Jour., 1879, Vol. xi, p. 22. Melanotic cancer removed from the axilla by MacLeod. Case 10.-Von Mosetig-Moorhof, Ber. d. K. K. Kranken, Wieden, 1898, p. 190.

Case 11-R. A. Cleemann. Transactions Pathological So. ciety, Philadelphia, 1867, p. 151. "Female aged 70. "Lump" in axilla $1 \frac{1}{2}$ inches in diameter of four years duration. Excised. A year later another lump appeared between the cicatrix and the breast. Both tumors pronounced epithelioma, the latter described as composed of a half dozen hard, rounded bodies in size from a split pea to a marble, making a single mass. The appearance of the mass and the skin led to the suggestion that the origin was in the appendages of the skin"the sweat glands."

Case 1\%.-C. F. Maunder, Transactions Pathological Society, London, 1862, Vol. xii, p. 229. Male aged 30. Open cancerous ulcer involving the axillary artery, not excised. Began as a lump in the axilla one year before, every clinical feature of carcinoma, but not demonstrated microscopically.

Case 13.-R. Alba, Espana Med.. Madrid, 1862, Vol. vii, p. 388. Axillary cancer. Extirpation by Prof. Natalis Cano. Reported cured.

Case 14. $\mathrm{S}$. Benavides, Chron. d' I Hosp., Madrid, 1856, Vol. iv, p. 206. Occult cancer and scirrhous tumor in the right axilla. Extirpation.

Case 15.-H. Ohm, Deutche Klinek., 1854, Vol. vi, p. 288. Female aged 40. Tumor arose from birthmark in axilla which had been accidentally abraided and ulcera ted a year previously. Other tumors developed in the axilla which proved to be of the lymphatics. The tumor was removed and it appears that the breast was not affected.

Case 16.-M. Marjolin, Bulletin de In Societé Chirurgie. Paris, 1862, Vol. iii, p. 410. Female aged 57. Left axilla; small painless tumor several months duration. This was extirpated and consisted of three distinct nodules. The microscopic examination was made by $M$. Robin. He remarks that the tumors are of a very rare species. His report, together with the clinical evidence and grose appearances given is almost conclusive that the case was one of primary carcinoma of the large sweat glands if interpreted in the light of today.

Case 17.-R. W. Smith, Dublin Medical Journal, 1838, Vol. xii, p. 65. Female aged 30. A hard, movable, painless tumor appeared in right axilla. Afterward the axillary ves sels and surrounding tissues became involved. One year and some months later a tumor was noticed in the breast. No operation. Autopsy showed carcinoma of the stomach and other viscera. The author reports the case as one of primary carcinoma of the axillary glands.

Case 18. - M. Marrotte, Jour. de Med. et Chirurgie, Vol. iv, p. 107, 1831. Male aged 22. Tumor filled right axilla. Extirpated and examined microscopically. Report says several forms of cancer and cysts full of blackish fluid were found. It is questionable whether this was not a case of sarcoma.

In a given case of carcinoma, originating in and apparently confined to the axilla, established surgical principles imperatively require wide removal of integument, fat and lymphatic tissue from the axilla and of the latter two structures along the border of the pectoral muscles to the breast, whether apparently in. vaded by the disease or not, and in most cuses some of the muscular tissue, as well. But it becomes a very important practical question whether the breast itself should or should not be included in the operation. It would be the safer course to remove the breast in all cases, but some exception can be made to this general rule consistent with good surgery, the question hinge. 
ing on the age of the patient, the extent of the disease, and the length of time it has existed.

\section{CONCLUSIONS.}

1. Primury carcinoma of the axilla is probably more frequent than the small number of recorded cases would seem to indicate.

2. When present it originates, $a$, in the large tubular convoluted sweat glands peculiar to this region, $b$, in supernumerary mammary gland tissue more or less rudimentary, or $c$, in the true skin; and as to relative frequency in the order named.

3. When the disease appears first in the axilla and later in the mammary gland the most satisfactory and the most logical explanation is that there has been retrograde infection through the lymphatics from the axilla to the breast.

4. When the lymph glands and channels or other to tissues between the axillary tumor and the mammary gland are at all infected, or suspected, the gland should be removed along with the tumor and the intervening infected tissues.

5 . In any case in which the breast is not removed it should be carefully examined at short intervals for the first manifestations of disease.

$$
\text { Discussion. }
$$

Dr. Charles A. Powers of Denver-The practical import ance of this subject can not be overestimated, and it shows that in addition to the removal of the primary neoplasms of the breast, those of the axilla should be subjected to the same management. The rule is absolutely established that no part of the mammary gland is to be allowed to remain without a most thorough and careful examination. It is well known by all surgeons and is becoming more and more appreciated by physicians and the laity. Our success lies in early recognition and extircation. During the past year I have removed from the anterior axilla a nodule the size of a hen's egg. Clinically differential diagnosie could not be made between a benign and a malignant growth, and the pathologist who examined this specimen called it a supernumerary mammary gland, which was the seat of the fibro-adenoma, although it might just as well have been malignant.

Dr. OCHSNER of Chicago-At the inner limits of the axilla, and the lower edge of the pectoralis major muscle, there is a point at which I have seen three carcinomatous growths, and in each one the nodule was first movable underneath the skin, consequently it could not have originated from the sweat glands in the skin, nor from anything except glandular tissue. The only glandular tissue there would bea portion of the mammary gland, and cancer in this region can originate precisely as could epitheliomatous growths elsewhere. In this particu lar location, if the points in its development are observed, it is perfectly plain that the cancer must come from a supernu merary mammary gland. I have frequently found extensions of the mammary gland a considerable distance from the gland proper, and I cannot see why there should not be exterision in the axillary direction as well as in any other. Under these circumstances, the carcinoma would originate precisely the same as from any other lobule, only the lobule is slightly dis placed.

Dr. A. D. BEvax of Chicago-There are two possibilities that must be borne in mind, one of which is the occurrence of a small primary focus of carcinoma, which is overshadowed by the secondary growth. It may be that the primary growth is a very smail nodule in the mammary gland, while the secondary mass may be in the axilla. In one of Dr. Hirschfelder's cases, there were extensive deposits of carcinomatous tissue in the prostate without any primary lesion. I recently had a case in which I amputated the entire outer end of the scapula and clavicle for supposed sarcoma, but postmortem examination showed it to be a case of carcimona. In these cases we must imagine one of two possibilities; first, that there was a small primary focus overshadowed by the secondary mass, or second, the encapsulation of a piece of epiblastic tissue which has developed into carcinoma.

Dr. J. B. Murphy of Chicago, IJl.-In the cases observed by the author, I would like to ask if the tumor was situated deep primarily or superficial primarily, that is to say, was the skin movable over it in the early stages? Dr. Ochsner laid great stress on this point. We all know that we can find car- cinomatous growths in the sweat glands which may or may not have originated in the mammary glands, and every surgeon has noticed that suppurative foci may be found in connection with the skin. Upon opening these tumors they will be found to contain a caseous material, and are largely made up of invaginated portions of the epiblast. These cysts are very common and frequently do not appear to be attached to the skin.

Dr. William L. RoDMaN of Louisville-I would like to report a case similar to Dr. Graham's, which occurred in a male about 60 years of age, living in Jeffersonville, Ky., who was by occupation a ship carpenter. The case was unques. tionably one of scirrhous carcinoma of the axilla, which was removed, and as it was the first of the kind I had ever seen I followed it up until death. This case bears out the remarks of several of the speakers, and I am sure you will occasionally find primary carcinoma in the axilla, although most of these cases are doubtless sarcoma. Dr. Bevan makes a good point when he states that a very small lump in the breast may be overlooked and the growth in the axilla considered as primary when it is really secondary. All of us have seen cases of this kind, and I have had my attention drawn to it by patients. As to the treatment of these cases, I can add nothing to what has been said by the essayist, but would like to insist even more strongly on one point, and that is the danger of infection of the lesser pectoral, which should be removed. It seems to me that it is even more necessary in these cases to remove the glands than it would be the primary growth in the breast itself. Dr. GraHaM, in closing-Referring to the microscopic findings in Dr. Powers' case, it is stated that many cases of fibroadenoma, so-called, originate in these sweat glands. as well as in the axilla and the mammary gland, and it is probable that most fibro adenoma originate in these glands. Dr. Bevan's statement is exactly opposite to what I claim, and there is no reason to my mind why a focus in the prostate should not be secondary as well as primary. It is true we may have a primary focus in the axilla. I believe you will admit that we do have tissue in the axilla capable of giving rise to primary carcinoma, and one of my cases proves this. With regard to Dr. Murphy's questions, the integument in the second case I reported was movable over the tumor, while in the other case the mass was very large, and the skin was tense. It must be remembered that these sweat glands are under the skin and not in it. No doubt we can have a supernumerary mammary nodule in the male as well as in the female.

\section{POST-OPERATIVE INSANITY்.}

Presented to the Section on Surgery and Anatomy at the Forty-ninth Annual Meeting of the American Medical Association, held at Denver, Colo., June 7-10, 1898.

BY R. HARVEY REED, M.D.

SLPERINTENDENT AND SLRGEON-IN-CHARGE WYMING GENERAL HOSPITAL; PRESIDENT WYOMIXG STATE MEDICAL NOCIETY.

ROCK SPRINGS, WYOMING.

For want of a better term I have adopted this one to indicate certain mental aberrations following operations. That very slight operations are not infrequently followed by severe attacks of insanity is beyond a question; at the same time the most severe operations on those who are insane are frequently followed by the return of their normal mental faculties.

Why this unfortunate complication should follow certain operations in both male and female is a question which up to the present time has not been fully settled from a pathologic standpoint. Statistics on this important subject are severely wanting, and it is believed on the part of the writer, that notwithstand. ing a few cases of post-operative insanity have been reported from time to time in the journals, a great many more have not been reported, possibly for the want of knowledge as to their cause, or maybe a hesitancy on the part of the operator to announce to the world that he has operated a certain case which has been followed by some form of insanity. The fact that we do have these cases occurring and that their causes are illy understood is certainly a sufficient excuse for having selected this subject, the study of which we hope will throw more light upon this important clinical question. 